\title{
0 uso das metodologias ativas para melhoria nas práticas de ensino e aprendizagem
}

\author{
Lara Miguel Batista' \\ Virginia Mara Próspero da Cunha²
}

Resumo: O presente artigo, de cunho bibliográfico, traz, em seu bojo, os efeitos do uso das metodologias ativas nas práticas de ensino e aprendizagem. A difusão do uso de tecnologias tem gerado transformações no âmbito da educação e as práticas pedagógicas tradicionais ainda são utilizadas com muita frequência. Como alternativa à prática tradicional, surgem as metodologias ativas, que possibilitam ao estudante atuar de maneira ativa na construção de seu conhecimento. Objetiva-se aprofundar teoricamente as reflexões sobre a formação docente e as crenças no processo de formação, apontando as possibilidades e os benefícios no uso das metodologias ativas. Uma vez que o contexto atual é de pandemia mundial do novo coronavírus, e as desigualdades do sistema educacional brasileiro ficaram mais evidentes, os recursos tecnológico-pedagógicos contemporâneos, mostram-se fundamentais nas ações dos docentes para que os alunos não tenham maior prejuízo no seu processo de construção dos saberes.

Palavras-chave: educação; metodologias ativas; práticas pedagógicas; ensino-aprendizagem.

\section{The use of active methodologies in teaching and learning practices}

Abstract: This article, which is bibliographical in nature, brings, in its wake, the effects of the use of active methodologies in teaching and learning practices. The diffusion of the use of technologies has generated transformations in the scope of education and traditional pedagogical practices are still used very frequently. As an alternative to traditional practice, active methodologies

\footnotetext{
1 Mestranda em Educação pelo programa Mestrado Profissional em Educação da Universidade de Taubaté. Graduada em Educação Física pela Pontifícia Universidade Católica de Campinas. Integrante do Grupo de Pesquisa Educação: desenvolvimento profissional, diversidades e metodologias, vinculado à Universidade de Taubaté. E-mail: laramiguel.b@gmail.com

2 Doutora e mestre em Educação (Psicologia da Educação) pela Pontifícia Universidade Católica de São Paulo (PUC-SP). Docente no Mestrado Profissional em Educação da Universidade de Taubaté. E-mail: vimaracunha@gmail.com
} 
emerge, which enable the student to act actively in the construction of their knowledge. The objective is to theoretically deepen reflections on teacher training and beliefs in the training process, pointing out the possibilities and benefits of using active methodologies. Since the current context is of a worldwide pandemic of the new coronavirus, and the inequalities of the brazilian educational system have become more evident, contemporary technological-pedagogical resources are fundamental in the actions of teachers so that students do not have greater damage in the its process of construction of knowledge.

Keywords: education; active methodologies; pedagogical practices; teaching-learning.

A educação básica no Brasil passa por grandes desafios e desmontes das políticas, uma vez que o direito à educação é assegurado a apenas uma parcela da população. Entretanto, neste momento de pandemia mundial, trazida pelo novo coronavírus, as desigualdades no ensino ficaram ainda mais evidentes, de forma que os professores precisam incorporar estratégias pedagógicas de ensino para que haja o cumprimento das atividades educacionais propostas sem maiores prejuízos aos alunos (IPEA, 2020).

Este artigo pretende provocar reflexões sobre o uso das metodologias ativas para avanço nos processos de ensino e aprendizagem por meio de um processo teórico metodológico em que se sai do senso comum e se aprofunda o debate sobre os benefícios aos alunos e aos docentes no uso desse método.

De acordo com Beck (2018), o conceito de metodologias ativas surgiu recentemente com essa nomenclatura; no entanto, nos estudos dos intelectuais Vygotsky, Dewey, Knowles, Freire e Rogers, apesar de não citarem o termo, as ideias do método e a aplicação já eram defendidas.

Suhr (2016, p. 8) define que "as metodologias ativas são um conjunto de propostas diversas que têm em comum o fato de se contraporem à metodologia expositiva, considerada responsável pela postura passiva e heterônoma do aluno".

Segundo Sobral e Campos (2012), a metodologia ativa tem sua concepção baseada na educação crítico-reflexiva, com base no estímulo no processo de ensino-aprendizagem, resultando em um abarcamento por parte do aluno na busca pelo conhecimento. Ou seja, a proposta é incentivar que os alunos sejam os protagonistas, aprendam de forma autônoma e participativa, enquanto o professor é mediador na aprendizagem, sendo assim um trabalho colaborativo.

Colaboração essa que pressupõe, na negociação de responsabilidades, condições democráticas para que todos se expressem no momento das atividades, compartilhando suas vivências e experiências. Nela, os envolvidos tornam-se capazes de problematizar, analisar e compreender suas práticas, produzindo conhecimentos que podem transformar a realidade e gerar mudanças na cultura escolar (IBIAPINA, 2016). 
Roldão (2007) denomina como "geradores de especificidade" um conjunto de características, agregadores e fatores de distinção do conhecimento profissional docente, o saber ideal ante a função de ensinar e sua eficácia, sendo eles a mútua incorporação, capacidade analítica, mobilizadora e interrogativa, metaanálise e comunicabilidade.

Observa-se que os professores precisam se reinventar nestes tempos difíceis e de tantas incertezas, utilizando ainda mais esses geradores de especificidade em suas práticas. Ao lidar com variadas salas de aula e alunos, tais situações requerem uma postura e forma de trabalhar diferenciada, e isso ocorre devido à pluralidade e diversidade nos perfis de cada sala de aula e aluno. Nesse sentido, entende-se que o docente necessita sair de sua zona de conforto e buscar toda e qualquer situação de ação instrutiva, como explana Libâneo, Oliveira e Toschi (2007):

O conceito de docência passa a não se constituir apenas de um ato restrito de ministrar aulas [...] nesse novo contexto, passa a ser entendido na amplitude do trabalho pedagógico, ou seja, toda atividade educativa desenvolvida em espaços escolares e não escolares pode-se ter o entendimento de docência (LIBÂNEO; OLIVEIRA; TOSCHI, 2007, p. 23).

As metodologias ativas surgiram para se opor à lógica formal das práticas de ensino, que é baseada nas metodologias passivas em que o professor é o agente principal nesse processo, tendo como princípio proporcionar aos alunos diferentes ferramentas para colaborar com sua formação integral (TITTON, 2020).

Pensando-se nesse contexto atual de pandemia do coronavírus e como medida alternativa para continuidade das práticas educacionais da população, as escolas começaram a adotar metodologias diferenciadas de ensino, medidas essas que possuem características semelhantes às da Educação a Distância $(\mathrm{EaD})$, porém aplicadas a todos os níveis educacionais; ou seja, por autorização do Ministério da Educação (MEC), desde o ensino fundamental até o nível superior poderiam usufruir de recursos digitais como método de ensino-aprendizagem. De modo que Leal (2020) afirma que as atividades remotas contribuíram para a ininterrupção do ano letivo dos discentes, porém exigiu uma maior energia dos professores e dos alunos, sendo necessária uma participação mais ativa e dinâmica para o desenvolvimento das atividades.

Curry (2020) aponta algumas reflexões sobre o cenário educacional durante o período de pandemia. Uma das reflexões diz respeito à desigualdade estrutural, relacionada à possibilidade de acesso à era digital pelos discentes, o que pode gerar como consequência o abandono da escola. Ele ressalta também a importância da utilização das Tecnologias Digitais da Informação e da Comunicação (TDIC), que deveriam fazer parte da formação inicial e continuada dos professores, como forma de contribuir para o desenvolvimento e aprendizado dos alunos. Contudo, Castells (2006) salienta que, para compreender a sociedade contemporânea, é preciso considerar as tecnologias da comunicação e informação, e que hoje acabam por criar processos de inclusão e exclusão na educação. Especial- 
mente no Brasil, onde, devido ao seu passado escravagista, segundo Curry (2002), a educação não se impôs como uma necessidade social significativa para todos, de forma que a conquista desse direito ocorreu de forma tardia e com imensas desigualdades sociais.

O Estado brasileiro tem a educação como direito fundamental social (art. $6^{\circ}$ da Constituição Federal), porém sem qualquer efetividade, já que as desigualdades são evidentes. Em 2015, o Brasil adotou os Objetivos para o Desenvolvimento Sustentável (ODS) prescritos pela Organização das Nações Unidas (ONU), que estrutura a Agenda 2030, uma estratégia de ação para as pessoas, para o planeta e para a prosperidade, reconhecendo que a erradicação da pobreza é o maior desafio global e que visa garantir que os seres humanos consigam exercer seu potencial com dignidade e igualdade, em um ambiente sadio. Especificamente o ODS de número quatro visa garantir o acesso à educação inclusiva, de qualidade e equitativa, e promover oportunidades de aprendizagem ao longo da vida para todos. Esses objetivos que devem ser buscados em todas as áreas, especialmente das que tratam de formação de pessoas, como escolas.

Gatti et al. (2019) apontam que a profissão docente deixou de ser uma ação espontânea, para se tornar uma prática que demanda conhecimentos científicos e humanistas para a ação educacional. De modo que compreender a situação social que vivenciamos é fundamental para se pensar na educação das gerações presentes e futuras.

Em vista disso, deve-se refletir sobre a qualidade e o alcance que essa ação realmente obteve até o presente momento. A pandemia evidenciou a verdadeira realidade acerca da educação no Brasil, as desigualdades sociais e o despreparo por partes dos docentes e instituições, no uso de recursos didáticos e tecnológicos em suas práticas educacionais.

\section{0 processo de formação docente e as crenças}

Para Imbernón (2002), os cursos de formação inicial carecem não apenas de conhecimento profissional, mas também de outros aspectos fundamentais para se exercer a profissão docente. As instituições deveriam ser proativas, preocupadas com a mudança e inovação. Dessa forma, pode-se refletir que os cursos de formação de professores carecem de uma reestruturação para que possam oferecer aos seus estudantes uma base sólida, capaz de subsidiar os conhecimentos necessários para que os futuros docentes, ao chegaram a uma sala de aula, possam fazer uma articulação entre os saberes acadêmicos e profissionais.

Gatti et al. (2019) apontam que o processo formativo que estruturou a profissão docente acompanhou a lentidão com que a educação básica se desenvolveu no Brasil. Acrescentam que problematizar questões ligadas à formação de professores e ao trabalho docente possibilita pensar maneiras de mudança, pois o trabalho pedagógico é a essência das atividades escolares. 
Marcelo (2009) evidencia em seus estudos que algumas características da profissão e da identidade docente são influenciadas por aspectos pessoais, sociais e cognitivos, pois o desenvolvimento profissional ocorre em um processo longo e integra diferentes tipos de experiências, sendo elas individuais e coletivas. E que as crenças que os professores carregam podem influenciar a maneira com que eles aprendem e os processos de mudanças que possam começar.

Guskey e Sparks (2002) indicam que a resistência à mudança por parte dos docentes é tão colossal que os professores só mudam suas crenças quando comprovam, na prática, a utilidade de novos métodos que se queiram desenvolver.

Para compreender as crenças no desenvolvimento profissional docente, é essencial que seja feita uma análise profunda nos processos que levam os professores a aprender e a ensinar, considerando sua historicidade e trazendo alguns elementos que estão presentes na constituição desse sujeito. Como apontam Aguiar e Ozella (2013), para entendê-lo é necessário compreender esse docente como um ser social e singular, síntese de múltiplas determinações, e que se relacionando socialmente constitui sua singularidade. Ou seja, esses professores, quando chegam aos cursos de formação inicial, carregam consigo suas experiências e vivências anteriores, e as instituições possuem a árdua missão de oportunizar uma base de conhecimentos sólida e desnaturalizar as crenças sociais, hereditárias, pessoais e limitantes que possam vir a intervir no processo de formação, visto que esses aspirantes a professores serão no futuro formadores de pessoas, agentes transformadores. Morgado (2011) ressalta que um dos pontos de resistência às mudanças da escola e da cultura dos docentes está ligado ao currículo, por ser baseado na lógica nacional como forma de controle dos níveis do conteúdo e pela forma com que esse conteúdo é repassado pelos professores, que são colocados como meros técnicos curriculares, à base do funcionalismo público, sem muito poder de autonomia em suas aulas. Portanto, além de refletir sobre as propostas de reestruturação na formação de professores, deve-se pensar também em uma forma para que esses docentes sejam capazes de assumir seu papel como profissionais especialistas no processo de ensino-aprendizagem, comprometidos com o aperfeiçoamento de seus saberes através da formação continuada a fim de contribuir para o desenvolvimento de sua prática docente.

Nesse sentido, Huberman (1989, p. 42) aponta algumas tendências gerais do ciclo de vida dos professores, indicando algumas fases que esses docentes passam ao longo da carreira. Há um período que o autor chama de "diversificação", em que os professores já passaram pelo período de estabilização e possuem uma consolidação de sua prática pedagógica. São "os mais motivados, os mais dinâmicos, os mais empenhados nas equipes pedagógicas ou nas comissões de reforma (oficiais ou 'selvagens') que surgem em várias escolas".

De acordo com Shulman e Shulman (2016), existem algumas características do professor competente e que, além disso, é necessário que o professor esteja disposto a pensar em um processo di- 
ferente de dar aulas e no processo de aprendizagem dos alunos, pois só assim será possível promover comunidades de aprendizes (PCA), baseando-se no processo de reflexão crítica.

Sendo assim, a reflexão se mostra fundamental nos processos de mudança que as práticas docentes podem vir a proporcionar para os alunos.

\section{Possibilidades e benefícios das metodologias ativas}

A Base Nacional Comum Curricular (BNCC) estabelece conhecimentos, competências e habilidades que se esperam que todos os estudantes desenvolvam ao longo da escolaridade básica. Objetivando propósitos que direcionam a educação brasileira para a formação humana integral e para a construção de uma sociedade justa, democrática e inclusiva, é balizadora da qualidade da educação no Brasil por meio do estabelecimento de um patamar de aprendizagem e desenvolvimento a que todos os alunos têm direito.

Para Moran (2013), o mundo contemporâneo vive um momento diferenciado do ponto de vista do ensinar e aprender. Aprendemos de várias formas, em redes, sozinhos, por intercâmbios, em grupos etc. Para ele, essa liberdade de tempo e de espaço em processos de aprendizagem configura um novo cenário educacional em que várias situações de aprendizagem são possíveis com a ajuda das metodologias ativas.

Há muitos estudos comprovando os benefícios do uso das metodologias ativas no processo de ensino e aprendizagem dos alunos. O psiquiatra estadunidense Willian Glasser desenvolveu uma teoria da pirâmide de aprendizagem, onde evidencia a otimização na retenção dos conteúdos pelos alunos.

Figura 1 - Pirâmide de aprendizagem

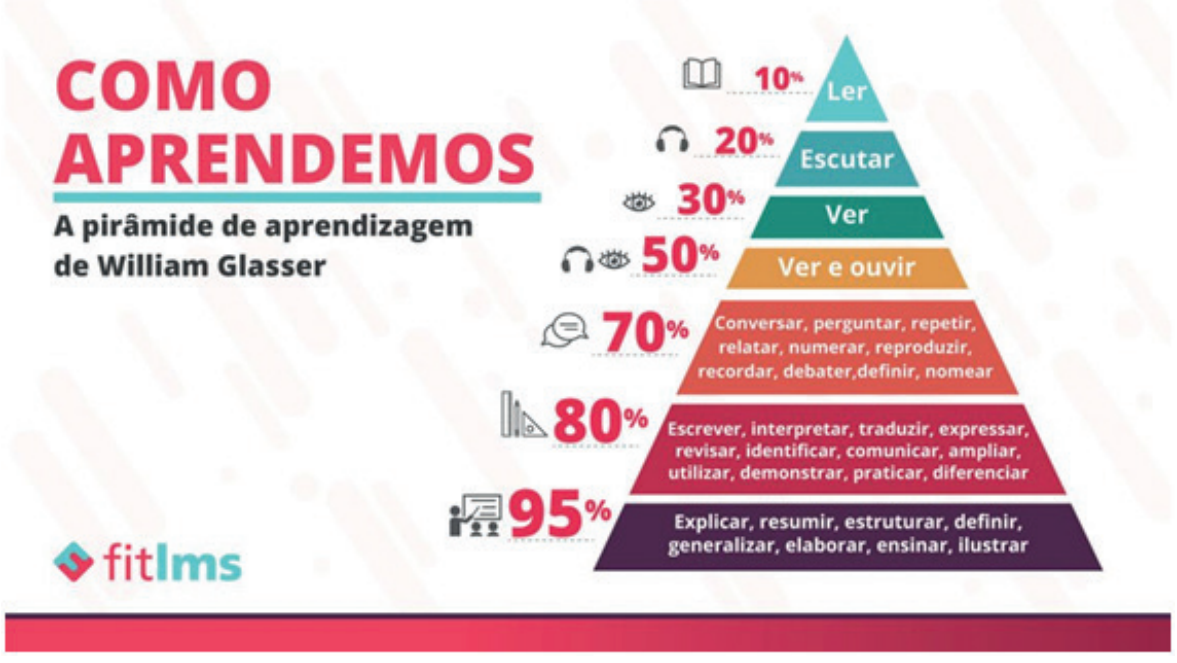

Fonte: https://mvceditora.com.br/2020/07/06/a-importancia-das-metodologias-ativas-para-a-aprendizagem/ 
A Figura 1 expõe, na parte superior da pirâmide, as metodologias passivas do processo de ensino e aprendizagem e na parte inferior, as metodologias ativas, confirmando que, para o aluno ter uma maior fixação do conteúdo, se faz necessária mais interação no processo de ensino.3Para Cohen (2017), o uso das metodologias ativas tem como premissa que apenas ver e escutar um conteúdo de maneira apática não é o suficiente para absorvê-lo. É necessário que seja discutido e experimentado até que o aluno possa dominar o assunto, socializar com seus colegas e até mesmo ensiná-lo.

Garofalo (2018) parte do princípio de que, na utilização desse método, o aluno seja responsável pela construção do seu conhecimento, sendo participante ativo no centro desse processo.

Os docentes têm como possibilidades trabalhar com a aprendizagem baseada em problemas, sendo o termo em inglês Project Based Learning (PBL), que tem como intuito que os alunos assimilem os conteúdos através de uma resolução coletiva de uma temática específica, de maneira a incentivar a habilidade de investigar, refletir e criar perante uma situação. Ao mesmo tempo, o docente atua como mediador na aprendizagem, motivando os alunos na construção de conhecimento pautando-se na reflexão-crítica. Como também na aprendizagem baseada em projetos, que possui fundamentos da PBL e tem como característica que os alunos "coloquem a mão massa", ou seja, percorram caminhos por si próprios até chegar à resolução do problema (GAROFALO, 2018).

Ainda segundo a autora Garofalo (2018), há outros dois tipos de metodologias ativas que propiciam o trabalho em grupo e colaborativo. São eles a aprendizagem entre times, sendo o termo em inglês Team Based Learning (TBL), que tem como base dividir os alunos em equipes e posteriormente compartilhar e socializar as ideias com a turma. A outra possibilidade é a sala de aula invertida, Flipped Classroom, que tem como objetivo substituir os modelos tradicionais de aulas expositivas. Nesse modelo, é possível mexer na disposição das carteiras, optar por não as usar e também, nesse contexto atual de pandemia, disponibilizar o conteúdo prévio da aula para o aluno, permitindo que ele interaja com colegas, propiciando um maior interesse sobre o conteúdo, resultando na construção do seu próprio aprendizado.

Rocha (2014) evidencia em seus estudos que alguns docentes resistem à concepção de antecipar o acesso ao conteúdo da sala de aula invertida, sob a alegação de que parte dos seus alunos não possui acesso à internet, seja por falta de tempo ou mesmo por não possuírem banda larga. Tal reação pode representar a necessidade de mais aprofundamento sobre o real objetivo da aplicação do método e dos elementos de contexto que podem interferir positivamente ou negativamente nos resultados da aplicação desse método.

\footnotetext{
$3 \mathrm{O}$ artigo intitulado The diffusion of the learning pyramid myths in academia an exploratory study - traduzido como A difusão dos mitos da pirâmide de aprendizagem em academia: um estudo exploratório, aponta que embora existam inúmeras versão difundidas, da pirâmide de aprendizagem, algumas são erroneamente atribuídas ao educador norte-americano Edgar Dale e aos psicólogos norte-americanos Jerome Bruner e William Glasser. Uma vez que as primeiras versões das pirâmides de aprendizagem não possuem origem conhecida, e que a mesma para ser validada, apresentada e difundida, deve partir da realidade e possuir rigor científico no campo estudado.
} 
Para Garofalo (2018, p. 3), são várias as vantagens do uso das metodologias ativas em sala de aula:"o principal é a transformação na forma de conceber o aprendizado, ao proporcionar que o aluno pense de maneira diferente (já ouviu falar em fora da caixa?) e resolver problemas conectando ideias que, em princípio, parecem desconectadas".

Na Figura 2, pode-se observar que as metodologia ativas propiciam que os alunos desenvolvam autonomia, ímpeto para resolução de problemas, noções do trabalho colaborativo e confiança para enfrentar situações complexas, na escola e na vida. Ele é o protagonista no seu próprio processo de aprendizagem, trabalha o senso crítico pautado nas suas experiências individuais e coletivas com o grupo, cria mecanismos de empatia ao respeitar pensamentos diferentes e, por fim, ganha responsabilidade com participação ativa. Isso significa que essas metodologias podem colaborar com o desenvolvimento tanto da dimensão cognitiva quanto socioemocional dos estudantes.

Figura 2 - Benefícios das metodologias ativas

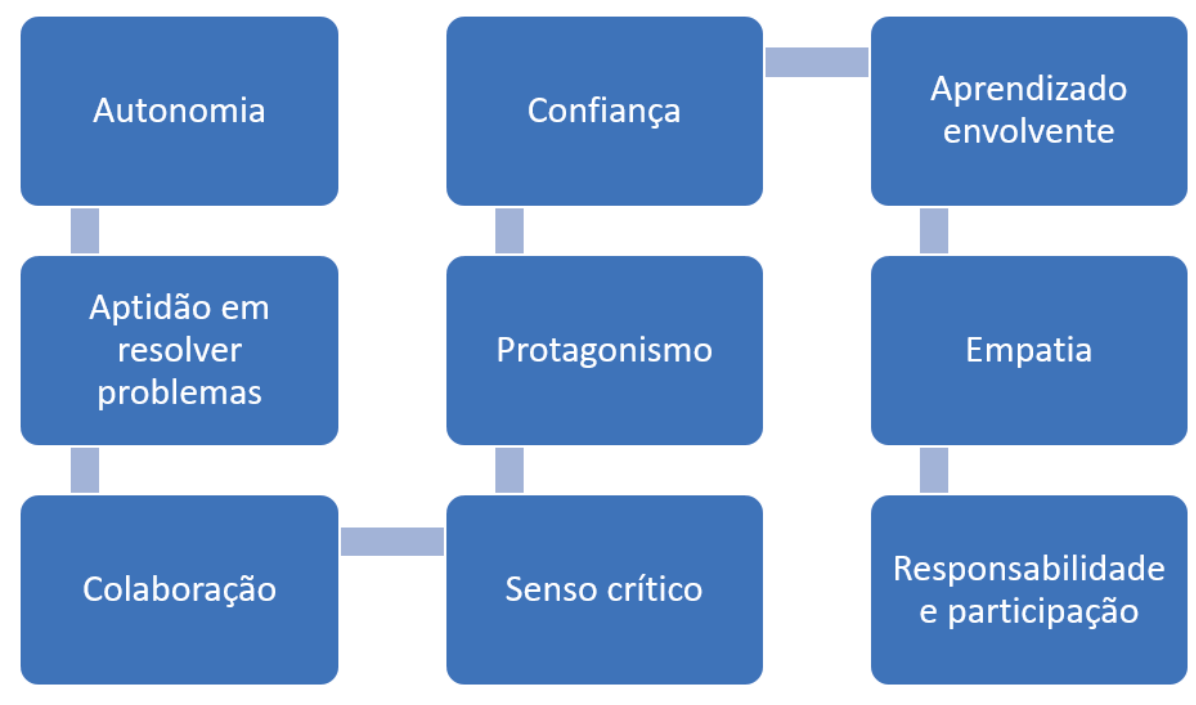

Fonte: https://novaescola.org.br/conteudo/11897/como-as-metodologias-ativas-favorecem-o-aprendizado

É nesse sentido que as metodologias ativas têm um papel valoroso, visto que estimulam a autonomia e a participação ativa do estudante na construção do conhecimento (GAROFALO, 2018).

Tardif e Raymond (2000) destacam que os saberes profissionais são plurais, oriundos de diversas fontes como escola, família e universidade. Por consequência, os benefícios do uso das metodologias ativas não se apresentam somente aos alunos, mas também para os docentes e a instituição. Quando se tem uma maior satisfação dos alunos com o ambiente da sala de aula, a devolutiva é positiva. Vygotsky (1996) sustenta que o desenvolvimento humano se dá por meio das relações sociais 
que o indivíduo mantém no decorrer da vida, ou seja, quando a relação professor-aluno é pautada no respeito e cooperação, propicia-se o crescimento de ambos.

\section{Considerações finais}

Tavares (2018) apresenta estudos nas áreas da neurociência e da psicologia da educação que argumentam que a construção do conhecimento, a maneira como a memória de longo prazo retém as informações e como as utiliza para apreender os fenômenos e resolver processos seriam favorecidos pela maneira como essas informações são exibidas ao cérebro, ou seja, como são ensinadas. De modo que quando se utiliza as metodologias ativas, a escola estaria propiciando a formação das habilidades de investigação, reflexão e autonomia na busca por conhecimento, assim como pensamento crítico e aptidão para resolução de problemas. Estimulando o desenvolvimento de habilidades de comunicação, trabalho em grupo, resiliência, colaboração, responsabilidade e proatividade.

Levando-se em consideração esses aspectos, foi possível destacar a existência de vários benefícios tanto para os alunos como para os professores e, por conseguinte, às instituições, com a utilização das metodologias ativas.

Portanto, a aplicação de metodologias ativas de aprendizagem tem um papel importante para a educação, especialmente no Brasil, onde o setor necessita de transformações substanciais, sendo necessário não somente investir em bons conteúdos, mas ter consciência de que aprimorar os métodos usados para educar é algo extremamente fundamental quando se pensa na formação integral dos indivíduos, para uma educação justa, acolhedora, inclusiva e emancipatória para gerações presentes e futuras.

\section{Referências}

AGUIAR, W. M. J.; OZELLA, S. Apreensão dos sentidos: aprimorando a proposta dos núcleos de significação. Revista brasileira de estudos pedagógicos, Brasília, v. 94, n. 236, p. 299-322, jan.-abr. 2013.

Base Nacional Comum Curricular. Disponível em: https://bit.ly/3gSkcRJ. Acesso em: 30 set. 2020.

BRASIL. Constituição. Constituição da República Federativa do Brasil. Brasília, DF: Presidência da República, 1988. Disponível em: https://bit.ly/3vL1QYy. Acesso em: 08 jul. 2020.

BECK, C. Metodologias ativas: conceito e aplicação. 2018 Disponível em: https://bit.ly/3iUycgJ. Acesso em: 15 set. 2020.

CASTELLS, M. A sociedade em rede: do conhecimento à política. In: CASTELLS, M.; CARDOSO, G. (Org.). A sociedade em rede: do conhecimento à acção política. Lisboa: Imprensa Nacional, 2006, p. 17-30.

COHEN, Ma. Alunos no centro do conhecimento. 2017. Disponível em: https://bit.ly/3vl6xlF . Acesso em: 15 set.2020. 
CURRY, C. R. J. Direito à educação; direito à igualdade; direito à diferença. Cadernos de pesquisa, São Paulo, n. 116, p. 245-262, jul. 2002.

CURY, C. R. J. Educação escolar e pandemia. Pedagogia em ação, Belo Horizonte, v. 13, n. 1, 2020.

GAROFALO, D. Como as metodologias ativas favorecem o aprendizado. 2018. Disponível em: https:// bit.ly/3vFonFX. Acesso em: 23 set. 2020.

GATTI, B. A. et al. Professores do Brasil: novos cenários de formação. Brasília: Unesco, 2019.

GUSKEY, T. R.; SPARKS, D. Linking professional development to improvements in student learning. Trabalho não publicado, apresentado no Annual Meeting of the American Educational Research Association, New Orleans, 10-5 abr. 2002.

HUBERMAN, M. O ciclo de vida profissional dos professores. In: NÓVOA, A. (Org). Vida de professores. Porto: Porto Editora, 1989, p. 31-61.

IMBERNÓN, F. Formação docente e profissional: formar-se para a mudança e a incerteza. Coleção Questões da Nossa Época, no 77.2. São Paulo: Cortez, 2001.

IBIAPINA, I. M. L. M. Reflexões sobre produção do campo teórico-metodológico das pesquisas colaborativas: gênese e expansão. In: IBIAPINA, I. M. L. M.; BANDEIRA, H. M. M.; ARAUJO, F. A. M. (Orgs.). Pesquisa colaborativa: multirreferenciais e práticas convergentes. Teresina: EDUFPI, 2016, p. 33-64.

Ipea - Instituto de Pesquisa Econômica Aplicada. Nota técnica - A infraestrutura sanitária e tecnológica das escolas e a retomada das aulas em tempos de covid-19. 2020. Disponível em: https:// bit.ly/2TOzBL9. Acesso em: 15 nov. 2020.

LEAL, P. C. S. A educação diante de um novo paradigma: ensino a distância (EaD) veio para ficar. Gestão \& Tecnologia, v. 1, n. 30, p. 41-43, jan.-jun., 2020.

LIBÂNEO, J. C.; OLIVEIRA, J. F.; TOSCHI, M. S. Educação escolar: políticas, estrutura e organização. São Paulo: Cortez, 2007.

MARCELO, C. Desenvolvimento profissional docente: passado e futuro. Revista de ciências da educação, n. 8, p. 7-22, jan.-abril 2009.

MORAN, J. M. Razão e emoção: componentes fundamentais do conhecimento. $5^{\circ}$ Simpósio hipertextos e tecnologias na educação. $1^{\circ}$ Colóquio Internacional de Educação com Tecnologias. Recife: UFPE, 2013. Entrevista a Karla Vidal. Disponível em: https://bit.ly/2SP4Nd7. Acesso em: 20 set. 2020.

MORGADO, J. C. Identidade e profissionalidade docente: sentidos e (im)possibilidades. Ensaio: avaliação e políticas públicas em educação, Rio de Janeiro, v. 19, n. 73, p. 793-812, out.-dez. 2011.

ROLDÃO, M. C. Função docente: natureza e construção do conhecimento profissional. Revista brasileira de educação, Rio de Janeiro, v. 12, n. 34, p. 94-103, jan.-abr. 2007.

SOBRAL, F. R.; CAMPOS, C. J. G. Utilização de metodologia ativa no ensino e assistência de enfermagem na produção nacional: revisão integrativa. Revista da escola de enfermagem da USP, São Paulo, v. 46, n 1, p. 208-218, fev. 2012.

SHULMAN, L. S.; SHULMAN, J. H. Como e o que os professores aprendem: uma perspectiva em transformação. Cadernos Cenpec, São Paulo, v. 6, n. 1, p. 120-142, jan.-jun. 2016. 
SUHR, I. R. F. Desafios no uso da sala de aula invertida no ensino superior. Revista transmutare, Curitiba, v. 1, n. 1, p. 4-21, jan.-jun, 2016.

TARDIF, M.; RAYMOND, D. Saberes, tempo e aprendizagem no magistério. Educação \& sociedade, v. 21, n. 73, p. 209-244, dez. 2000.

TAVARES, P. A. Metodologias ativas: entenda como elas favorecem a aprendizagem. 2018. Disponível em: <https://bit.ly/2SIm3Xi>. Acesso em: 23 set. 2020.

TITTON, L. A. Aprendizagem ativa: a história é outra. 2020. Disponível em: https://bit.ly/3wGNMR0. Acesso em: 15 nov. 2020.

VYGOTSKY, L. S. A formação social da mente. Rio de Janeiro: Martins Fontes, 1996. 